\title{
Enquanto eles seguem livres
}

\author{
Ana Cecília Araújo Soares de Souza ${ }^{1}$
}

Resumo: $\mathrm{O}$ artigo reflete sobre as ações das artistas Regina José Galindo e Bartira Dias, que estão alinhadas a uma postura ética, estética e política de resistência a misoginia na sociedade atual. A primeira lança um olhar sobre a violência sofrida pelas mulheres Maia-Ixil na Guatemala. A segunda, posiciona-se criticamente contra a exploração sexual no Brasil.

Palavras-chave: peformance, feminicídio, Regina José Galindo, Bartira Dias

\section{While they go free}

Abstract: "The article reflects on the actions of the artists Regina José Galindo and Bartira Dias, who are aligned with an ethical, aesthetic and political stance of resistance to misogyny in today's society. The first takes a look at the violence suffered by Mayan-Ixil women in Guatemala. The second, takes a critical stand against sexual exploitation in Brazil.

Keywords: peformance, femicide, Regina José Galindo, Bartira Dias

1 Doutoranda pelo Programa de Pós-Graduação em Artes (PPGArtes) da Universidade Federal de Minas Gerais (UFMG), na linha de pesquisa: Artes Visuais, Plásticas e Interartes. Mestre pelo Programa de Pós-Graduação em Artes- PPGARTES ICA|UFC. Especialista em Teorias da Comunicação e da Imagem - Universidade Federal do Ceará (UFC), em 2007. Graduada em Comunicação Social - Jornalismo - Universidade de Fortaleza (Unifor), em 2008. Uma das idealizadoras da Editora Reticências. Tem experiência nas áreas de artes visuais, crítica de arte, curadoria e jornalismo cultural. Universidade Federal de Minas Gerais (UFMG/PPGArtes). E-mail: anacicasoares@gmail.com. ORCID: https://orcid.org/0000-0001-6984-0428. Lattes iD: http://lattes.cnpq.br/8833776809003783. Fortaleza e Belo Horizonte, Brasil 
O que Fortaleza tem em comum com a Cidade da Guatemala? Para além das belezas naturais pertencentes a cada uma delas, há uma triste realidade a assombrar suas histórias. Nessas cidades, o número de feminicídio cresce diariamente, marcando com dor e descaso as vidas engolidas pela violência. A impunidade é alimentada pela burocracia e pela ignorância que rege o sistema diante da fragilidade de políticas públicas em defesa dos direitos da mulher.

Paraíso tropical banhado pelas águas cristalinas do Mar do Caribe, entremeado por lagos, montanhas e grande vulcões que ultrapassam os 4 mil metros de altitude; a Guatemala foi o principal centro da civilização Maia dos séculos IV ao IX. O lugar tem como uma de suas características a nítida oposição entre os indígenas de origem Maia (quase a metade dos habitantes), que possuem forte influência na cultura nacional, e a elite de descendência espanhola, detentora do controle da produção econômica e do poder político no país. Assim como as diversas nações latino-americanas, a desigualdade social é um dos problemas cruciais enfrentados pelos guatemaltecos. De acordo com o Programa das Nações Unidas para o Desenvolvimento (PNUD) ${ }^{1}$, o território é extremamente pobre, e nos últimos dez anos teve um crescimento econômico de apenas 2,4\%. A miséria é, inclusive, um dos motivos causadores da desnutrição crônica que afeta boa parte do público infantil.

Sem romper com o legado de violência instituído pelos regimes ditatoriais alastrados pela América Latina, a Guatemala concebeu um dos mais sangrentos da história. Seu algoz foi o general José Efraín Ríos Montt (1926 - 2018), famoso pelo sadismo e pela crueldade de seus atos. Antes de chegar ao poder, o militar participou, em 1954, do golpe de Estado que derrubou o presidente eleito democraticamente, Jacobo Arbenz. Com o apoio da CIA, a ação visava acabar com o projeto de reforma agrária em vigor porque estava afetando diretamente a empresa norte-americana United Fruit, grande proprietária de plantações de banana naquele país.

Nesse contexto, mais de duas décadas depois, Ríos Montt levaria a Guatemala a um novo golpe ${ }^{2}$, mas, desta vez, seria o próprio a assumir o poder.

1 Mais informações sobre o contexto geral da Guatemala se encontra disponível em: <https://www.undp.org/content/dam/guatemala/docs/publications/UNDP_gt_ ODM_2dolnforme.pdf> Acesso em: 31 mar. 2020.

2 O golpe de 1982 foi parte da Guerra Civil da Guatemala (1960-1996). Os EUA e outros 
De 23 de março de 1982 a 8 de agosto de 1983, governou a sangue e a ferro o povo guatemalteco. 0 general, por intermédio dos grupos paramilitares, criados por ele na época, provocou o genocídio de mais de 200 mil pessoas e a destruição completa de mais de 400 aldeias, pondo em prática uma política de horror, tortura e repressão às populações indígenas em favor das empresas transnacionais. Tornando-se, portanto, um dos mais importantes aliados do ex-presidente dos Estados Unidos Ronald Reagan na região.

Dentre às principais vítimas de suas atrocidades estava as mulheres da etnia Maia-Ixil. Os crimes hediondos perpetrados contra elas mostram, por exemplo, que o estupro era uma prática generalizada, sistemática e premeditada, usada como arma de guerra e parte do regime contra insurgência do governo:

Ouvi um dos soldados dizer que Ríos Montt mandou parar todo esse lixo Ixil, porque a gente colaborava com os guerrilheiros [...]muitos soldados nos estupraram. Eles me abusaram a noite toda, era uma média de vinte soldados, mas no final deixei de contar e perdi a consciência [...] me sinto muito triste, estou sempre doente e não saio de casa. Meu coração dói (tradução da autora). ${ }^{3}$

Devido às muitas lutas de órgãos ligados aos direitos humanos, sobretudo, a denúncia feita por Rigoberta Menchú, ativista indígena ganhadora do prêmio Nobel da Paz (1992); o ex-ditador Ríos Montt, em maio de 2013, foi julgado pela barbárie cometida, e condenado a 80 anos de prisão. Contudo, dez dias depois, a sentença promulgada foi anulada pela Corte de Constitucionalidade, a máxima instância jurídica da Guatemala, que ordenou um novo julgamento. Os advogados de defesa alegaram um diagnóstico de demência senil e uma série de outras complicações de saúde como uma maneira de tentar barrar um confronto judicial. O que de fato ocorreu, deixando o militar ileso a qualquer tipo de punição até a sua morte, por um infarto, em abril de 2018.

atores da comunidade internacional participaram desta iniciativa, com a justificativa de combater o socialismo na América Latina.

3 Testemunho de uma sobrevivente do massacre liderado por Ríos Montt, disposto no documento elaborado pela Federação Internacional de Direitos Humanos (FIDH) Genocídio em Guatemala. Ver referência bibliográfica. 


\section{Uma artista contra o ditador}

Regina José Galindo é daquele tipo de artista de energia vibrante e com coragem suficiente para transformar sua poética em instrumento crítico contra as agruras do mundo, principalmente, as da sua terra natal. De traços indígenas marcantes, Galindo não se esquiva de suas origens, ela as vive tão intensamente, sendo mesmo difícil dissociá-las de tudo aquilo a que se dedica fazer no campo artístico. Nascida na Cidade da Guatemala, em 1974, no auge da Guerra Civil, da qual seria, mais tarde, grande delatora; a artista por meio de sua obra nos permite acessar temáticas inquietantes sem que a clareza sucumba ao sensacionalismo. Suas performances são lugares de criação dos quais emergem complexidades, até então insuspeitadas, onde a artista dá forma às suas interrogações e sentimentos.

Galindo transforma seu corpo em uma superfície de projeção altamente crítica, refletindo a injustiça e a opressão de seu país. Segundo Fazzorali (2018), a performer recupera em suas ações a memória política da Guatemala, a corporeidade é o dispositivo de denúncia referente as discriminações raciais, de gênero e outros abusos implicados nas relações desiguais de poder presentes nas sociedades atuais. Em seus trabalhos, ela rumina temores, como aqueles impostos às mulheres Ixil, propondo uma revisão da experiência traumática pela qual elas passaram e ainda passam. Há feridas que são eternas, não se curam e estarão sempre a doer, ainda mais quando se defrontam com as barreiras da impunidade.

Mais precisamente há uma década, Galindo dava início ao seu confronto aberto com o ditador Ríos Montt. Tudo começou com a performance ¿Quién puede borrar las huellas? (2003), quando realizou uma caminhada do Centro da Cidade da Guatemala, com os pés descalços, marcando com sangue humano as calçadas, até a Corte Suprema e o Palácio Presidencial. O intuito era lembrar as vítimas do genocida e rejeitar a sua candidatura à Presidência da República, no ano de 2003. Apesar da Constituição da Guatemala vetar o envolvimento de ex-ditadores no processo eleitoral, o militar não só participou das eleições como chegou a conquistar o terceiro lugar nas urnas do país.

A reflexão de Regina José Galindo sobre a violência sofrida pelas mulheres na Guatemala amplia suas questões com a performance Himenoplastia. Em 2004, a artista se submeteu a uma cirurgia para a reconstrução do hímen, cujo processo foi todo gravado. Galindo buscou trazer para o debate o fato de que muitas mulheres na Guatemala e em outros países conservadores se submetem a essa prática como forma de se manterem "puras" 
Figura 1

A artista em diferentes momentos da performance ¿Quién puede borrar las huellas? (2003).

Fonte: https:// danilopezestetica. wordpress.com/ category/performance-regina-jose-galindo/
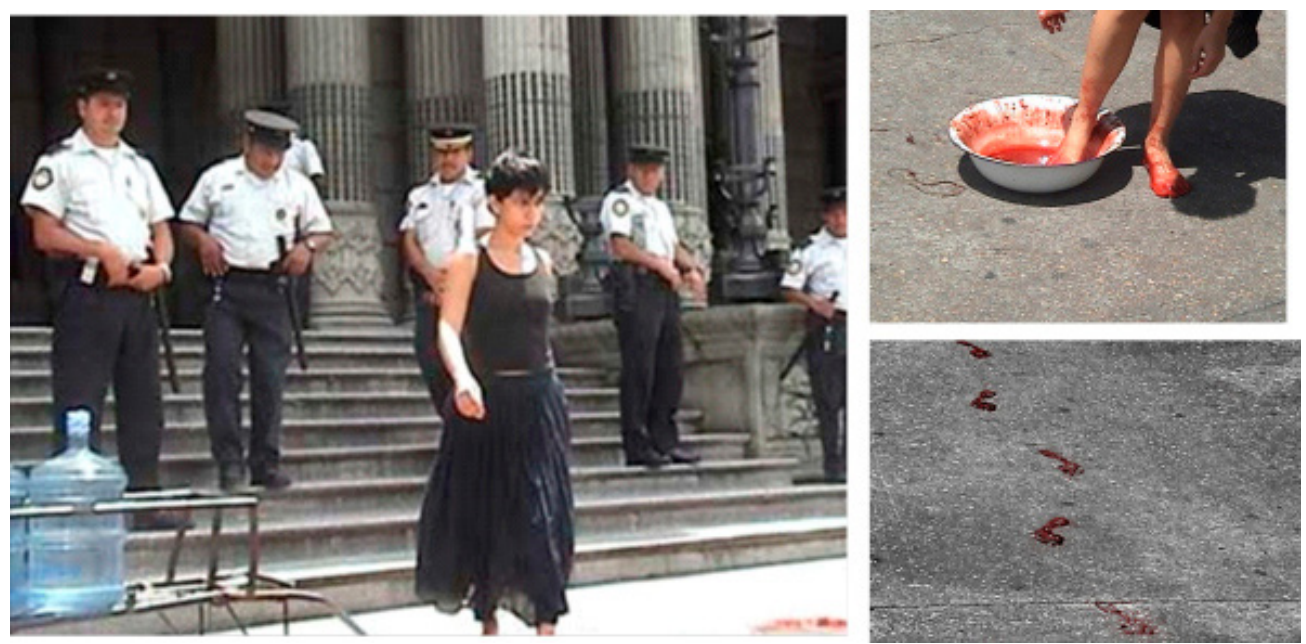

(virgens) para o casamento, ganhando, dessa forma, certo status social. Ou ainda, o caso das vítimas do tráfico sexual (crianças e adolescentes), obrigadas a passar pelo procedimento para adquirirem um "preço melhor" no "mercado".

\begin{abstract}
Um dia, em abril, eu estava lendo o jornal e vi um artigo sobre a reconstrução do hímen. Então, eu vi um anúncio classificado de um local para restaurar a virgindade. Fui lá e mostrei o meu trabalho para o médico que concordou deixar filmar o processo por uma certa quantia. Eu fui à clínica várias vezes para observar as mulheres que passavam por lá. Conversei com o médico várias vezes também, e ele me contou as histórias de muitas de suas pacientes. A maioria delas queria recuperar sua integridade para o casamento. Elas faziam isso para ganhar um certo status social. Em outros casos, crianças e adolescentes vítimas de tráfico sexual são operadas para obter um preço melhor. É preferível comprar uma menina virgem não apenas por causa de sua virgindade, mas também porque é considerada uma proteção melhor contra as DSTs. A operação foi rápida. Meia hora. Dolorosa. Caótica. Saí me sentindo feliz por ter acabado. No carro de Belia (a amiga que me acompanhava), comecei a sentir um líquido quente entre as minhas pernas, fluindo mais e mais a cada segundo que passava. Nós dirigimos de volta para a casa dela e eu coloquei uma espécie de fralda, mas nada poderia parar o fluxo. Então, fomos à clínica do meu ginecologista e de lá para o hospital. Tudo aconteceu tão rápido. Vestiram-me de camisola, deitaram-me numa cama, enfiaram um anestésico no meu braço e, enquanto eu mergulhava no sono, ouvia as enfermeiras a conversar entre si, sentindo pena de mim, como das muitas outras moças que tinham sido internadas no hospital com sangramento de um procedimento médico mal feito, seja um aborto ou uma Himenoplastia (tradução da autora). ${ }^{4}$
\end{abstract}

Em Mientras, ellos siguen libres (2007), Galindo aborda novamente a violência cometida às mulheres Ixil, desta vez fazendo menção aquelas que

4 Depoimento da artista, disponível em seu site. Consultar bibliografia. 
se encontravam grávidas na época do massacre. A ação é extremamente forte e seu impacto se torna maior pelo fato da artista, também, encontrar-se gestante, de oito meses, no momento de sua desenvoltura. A partir dos relatos das sobreviventes, Galindo constrói uma performance onde se põe na mesma posição na qual as mulheres eram colocadas por seus agressores: deitada de dorso com às mãos e os pés amarrados à cabeceira de uma cama-catre, feita de madeira produzida com couro cru e um colchão de palha. Para, em seguida, serem barbaramente violentadas a ponto de perderem seus filhos ou de não poderem mais engravidar tamanha a intensidade da agressão sofrida. Os estupros coletivos das indígenas grávidas tinham, portanto, o objetivo genocida: esterilizar de forma muito violenta a capacidade de reprodução das mulheres.

Figura 2 Mientras, ellos siguen libres (2007) denuncia a violência sexual sofrida pelas mulheres grávidas da etnia Maia-Ixil. Fonte: http://www. reginajosegalindo. com/

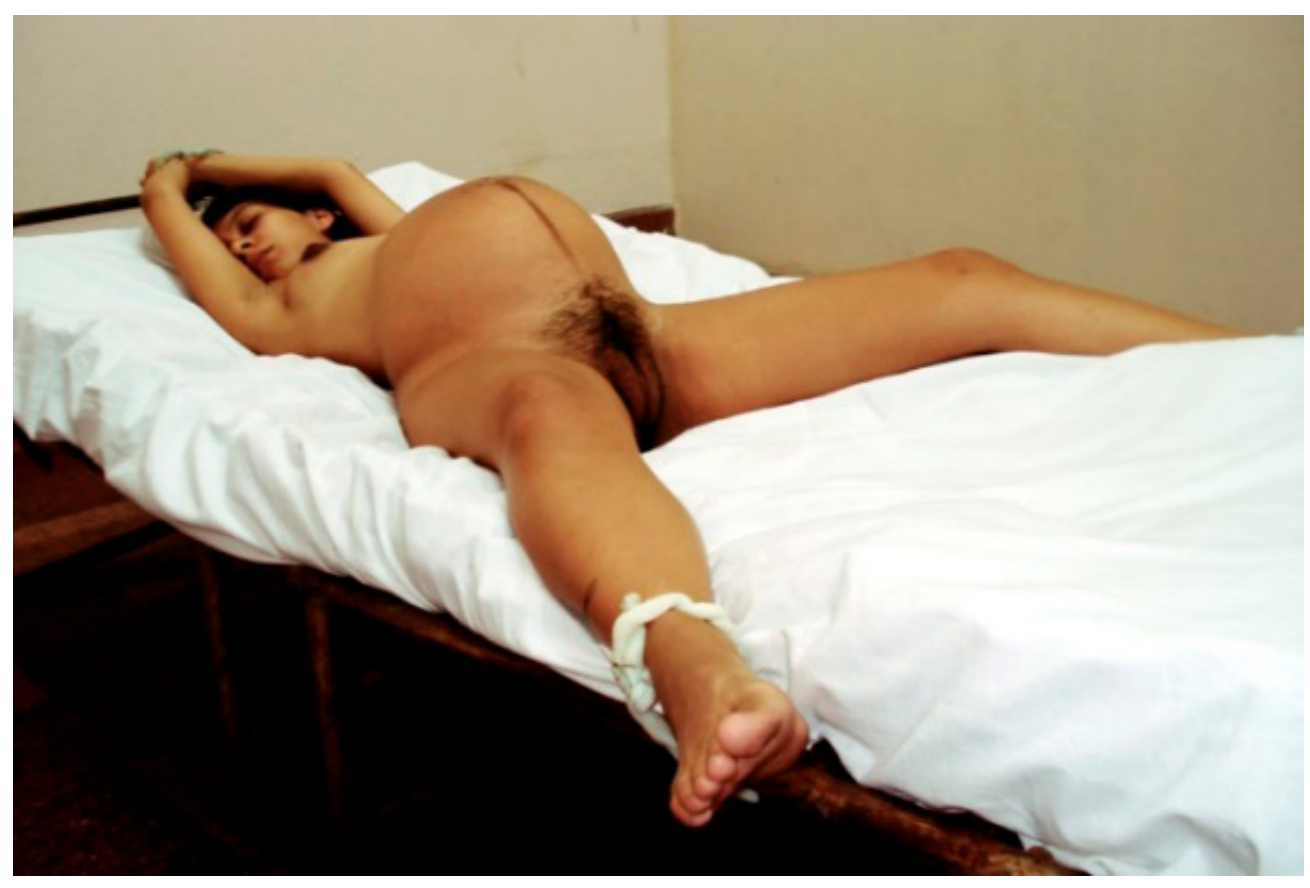

La verdad (2013) é outro trabalho denso e impactante que denuncia a impunidade de Ríos Montt diante da violência cometida contra o povo Maia-Ixil. Ao longo de uma hora e meia, a artista lê testemunhos de sobreviventes do conflito armado vivido na Guatemala, enquanto de instante em instante (uma média de sete vezes), um dentista a interrompe para Ihe aplicar doses regulares de anestésicos na boca. Com grande dificuldade, entre pausas e suspiros, Galindo prossegue com a leitura, e apesar de quase não poder mais articular as palavras devido o bloqueio muscular causado pela anestesia, seu propósito é mantido até o fim da última página corrida do arquivo. 
Essa performance potencializa o debate sobre a necessidade dos grupos marginalizados se colocarem como sujeitos de sua própria história. Algo que, nas palavras de Grada Kilomba, seria a saída da posição de objetificação para a esfera daquele que configura sua palavra. Uma vez que "estamos encarceradxs numa hierarquia colonial violentíssima" (2010, p. 27).

Como muitas artistas latino-americanas, Regina José Galindo apresenta o corpo como campo de batalha contra os parâmetros de representação regulados pelas convenções sociais e morais. Seus trabalhos nos possibilitam a visualização de uma estética problematizadora dos valores patriarcais e de combate a tirania de governos autoritários como o que foi imposto por Efraín Ríos Montt à Guatemala. Segundo Giunta (2018), a relação entre corpo e violência na América Latina é algo constantemente discutido nas produções artísticas devido ao cenário de ditaduras e outros conflitos repressivos presentes em sua história. Além disso, a região é, segundo a ONU Mulheres 5 , a mais perigosa para a população feminina, fora de uma zona de guerra. Cerca de nove mulheres são assassinadas por dia, vítimas de violência de gênero. $E$ dos 25 países do mundo com as taxas mais altas de feminicídio, 14 estão na América Latina e Caribe. Reflexo da ausência/

Figura 3

Regina José Galindo durante a performance $L a$ verdad (2013). Fonte: reginajosegalindo.com/
5 Mais informações sobre o assunto estão disponíveis em:< http://www.onumulheres. org.br/onu-mulheres/documentos-de-referencia/>. Acesso em: 31 mar. 2020. 
fragilidade na aplicação das leis e de um baixo investimento na infraestrutura requerida para a proteção das vítimas e a sanção aos agressores. Por isso, trabalhos como os de Galindo se tornam, cada vez mais importantes, dentro dessa conjuntura de modo a sensibilizar o debate e a formulação de políticas públicas consistentes para a causa.

Galindo coloca em crise estabilidades e dogmas, rompendo com qualquer tipo de estereotipo ou padrão preconcebido. Através da arte, a artista ressoa sua indignação diante "das metástases de nosso tecido social esgarçado" (FAZZORALI, 2018, p.67). Nela, a performance é a estratégia viva de mediação cultural que tira o espectador da zona de conforto para adentrar a realidade dura e cruel daqueles excluídos pelas classes mais abastadas. Ao passo em que, também, é a instância de reencontro com a esperança na dignidade humana. Nessa jornada por reconhecimento e igualdade, todo esforço é válido e a arte, principalmente, vem contribuindo com reflexões significativas para a causa. Segundo Taylor, devido sua aproximação com a vida, a performance vai trazer consigo "a possibilidade de desafio, até mesmo de autodesafio [...] Como termo que conota, simultaneamente, um processo, uma práxis, uma episteme, um modo de transmissão, uma realização e um modo de intervir no mundo" (2013, p. 44).

O assassinato de mulheres em contextos marcados pela desigualdade de gênero recebeu uma nomenclatura própria: feminicídio. Conforme o Mapa da Violência ${ }^{6}$ (2015), o Brasil é o quinto país como maior taxa de feminicídio no mundo. $E$, mesmo assim, o combate às raízes dessa violência extrema em território nacional, não se encontra no centro do debate público com a intensidade e a urgência que merecem ter (sem claro, desmerecer as conquistas que já tivemos, ao longo dos anos, pelos esforços dos movimentos feministas). Infelizmente, são frequentes os casos onde o crime realizado pelo parceiro ou "ex" é apresentado como um ato isolado, um momento de descontrole ou de intenso arrebatamento emocional onde o suposto comportamento de quem foi vítima do crime é apontado como a causa responsável da própria agressão sofrida pela mulher. Outro aspecto a se considerar é que, apesar de termos uma das legislações mais completas contra a violência sofrida pelas mulheres, o apoio estrutural para sua aplicabilidade é ainda bastante precário: existe uma carência tanto de profissionais quanto de

6 Dados publicados em: <https://dossies.agenciapatriciagalvao.org.br/feminicidio/ pesquisa/mapa-da-violencia-2015-homicidio-de-mulheres-no-brasil-flacsoopasomsonu-mulheresspm-2015/>. Acesso em: 31 mar. 2020. 
recursos no que diz respeito aos encaminhamentos previstos pela Lei Maria da Penha. Situação esta, que só vem piorando com o descaso e a falta de atenção dada pelo atual presidente do Brasil, Jair Bolsonaro, que, em diversas vezes, deixou explícito sua repugnância com a causa feminista. Chegando a fazer declarações que violam a dignidade das mulheres ao enaltecer a imagem estereotipada do Brasil, como sendo o paraíso sexual, onde as brasileiras estariam à disposição de homens estrangeiros, como objetos sexuais.

\section{Uma artista contra o turismo sexual}

De acordo com estudo realizado pela Organização das Nações Unidas (ONU), entre os anos de 2005 e 2011, no Brasil, o tráfico de pessoas atinge cerca de 2,5 milhões de vítimas, e, no mundo, obtém lucro médio de 32 bilhões de dólares anual, do qual 85\% advêm da exploração sexual. No cenário desenhado, Fortaleza está entre as cidades brasileiras com mais altos índices de violência sexual contra crianças e adolescentes, e ocupa o segundo lugar na rota de turismo sexual no país.

A partir desse contexto, a artista cearense Bartira Dias vem desenvolvendo uma pesquisa poética onde questiona o sistema de opressão e exploração imposto ao corpo feminino na sociedade contemporânea, denunciando especificamente a realidade do Estado onde vive. Em 2010, quando fazia parte do Coletivo PARE (Provocação Artística Ritual Experimental) ${ }^{7}$, ela participou de ação Frágil, realizada no Aeroporto Internacional Pinto Martins, para a Mostra Arte, Cidade e Direitos Humanos, da Secretaria de Direitos Humanos de Fortaleza, com o objetivo de denunciar, dentre outros aspectos, o turismo sexual naquela cidade. Durante esta performance, Bartira e mais onze artistas embalaram seus corpos com plástico, semelhante ao processo que fazemos no dia a dia para guardar alimentos; tendo na região dos seios, vagina e das nádegas, placas fixas com a palavra "frágil". Elas se concentraram em frente a porta de desembarque internacional e ficaram esperando um voo que vinha de Milão. Isso provocou reações diversas de alguns turistas estrangeiros: do espanto a xingamentos proferidos contra as artistas.

7 O coletivo PARE durou um ano (2010-2011), era constituído pelas artistas Naiana Cabral, Bartira Dias, Thatiane Paiva, Carolina Morais, Lívia Moreira, Diana Medina, Tatiana Valente e Tatiane Sousa. Um de seus principais objetivos era questionar como o capitalismo intervém nos corpos das mulheres e pensar a questão do consumo e da sociedade do espetáculo na sua relação com o gênero. Para a performance Frágil, o coletivo contou ainda com a participação da Cia. Ponto. 
Figura 4

Bartira Dias na performance $O$ dentro da pele para fora do ar (2012). Crédito: Janaína Teles

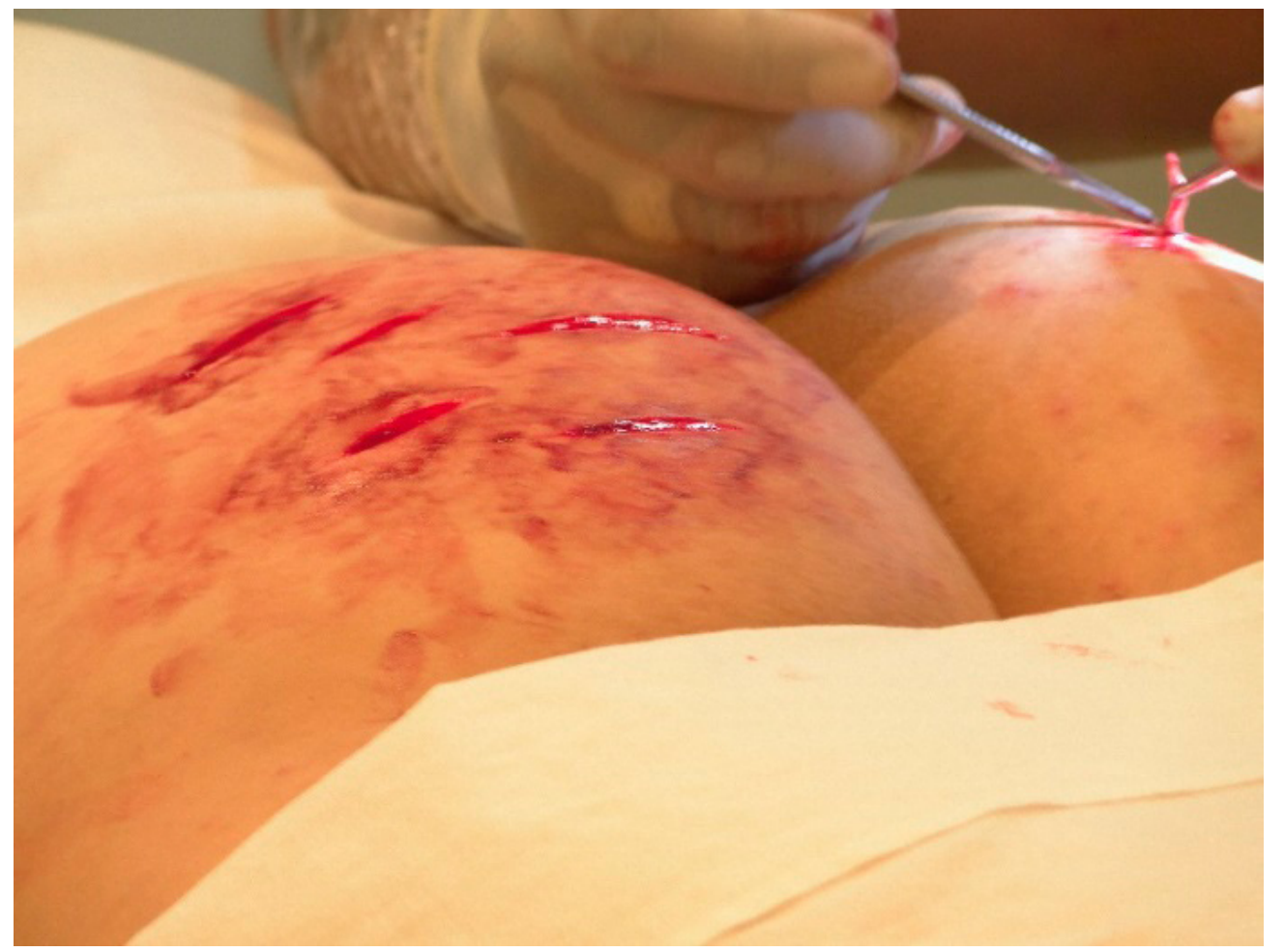

Segundo Dias, a mulher brasileira é estigmatizada, principalmente, na Europa e na América do Norte, como uma mercadoria meramente sexual de uma "sensualidade tropical exótica". "Esses homens pagam por serviços ilegais que vão de encontro aos direitos humanos e saem ilesos como colonizadores que exploram os colonizados para saciarem suas necessidades", nos explica a artista ${ }^{8}$.

Outro trabalho significativo é $O$ dentro da pele para fora do ar (2012), realizado no Centro Cultural Banco do Nordeste Fortaleza, que consiste em uma ação de transformação corporal, da série Ex-drógeno. Nela a performer busca ressignificar o elemento bunda, tratado como objeto da sexualidade feminina no Brasil, criando novas relações com o corpo, questionando seu uso enquanto produto e refletindo sobre a banalização e a violência de gênero que, por sua vez, são subestimadas na sociedade brasileira. $\mathrm{Na}$ performance, portanto, Dias tem a pele das nádegas cortada e cada "bife" é vendido numa irônica expressão da violência onde o dentro da pele se põe para fora, como carne morta e barata. É como se o tecido epitelial que ficasse para além da superfície se tornasse livre dos padrões, permitindo a 
desconstrução do corpo, do belo e do prazer normalizados. Com isso, seu trabalho cria fissuras, linhas de fuga, desvios dentro de um sistema cruel e regulador. E conduz a produção de micropolíticas de resistência perante o machismo institucionalizado

Podemos dizer que tanto Galindo como Dias fazem parte de um conjunto de artistas latino-americana que tem atuado incansavelmente na busca por mudanças nesse cenário marcado pelo domínio patriarcal em prol de uma existência mais digna e igualitária para nós, mulheres. A arte é, pois, um importante instrumento de posicionamento crítico da qual é possível reinventar as narrativas sobre o feminismo, denunciar os abusos de poder e desconstruir estereótipos misóginos. Os trabalhos dessas duas artistas trazem uma poética feminista porque se encontram alinhados a uma postura ética, estética e política de resistência e criação de outras figurações para o corpo, a subjetividade e a existência da mulher.

\section{REFERÊNCIAS}

GALINDO, Regina José. Regina José Galindo. Disponível em: <http://www. reginajosegalindo.com/>. Acesso em: 31 mar. 2020.

GIUNTA, Andrea. A virada iconográfica: a desnormalização dos corpos e sensibilidades na obra de artistas latino-americanas. In: Mulheres radicais: arte latino-americana, 1960-1985. GIUNTA, Andrea; HILL, Cecilia Fajardo (Orgs.). São Paulo: Pinacoteca de São Paulo, 2018.

FABIÃO, Eleonora. Performance e teatro: poéticas e políticas da cena contemporânea. Sala preta, São Paulo: Programa de Pós-Graduação em Artes Cênicas (PPGAC) /USP, v.8, p. 235- 246, 2008.

Disponívelem:<http://www.revistas.usp.br/salapreta/article/ view/57373>. Acesso em: 31 mar. 2020.

FAZZOLARI, Cláudia. A performance de Regina José Galindo: luta e resistência na América Latina. Extraprensa, São Paulo, v. 11, n. 2, p. 58 68, 2018. Disponível em: <DOI: https://doi.org/10.11606/extraprensa2018.145508>. Acesso em: 31 mar. 2020.

FIDH - Federación Internacional de Derechos Humanos. Genocídio en Guatemala: Ríos Montt culpable. Disponível em: <https://www.fidh. org/IMG/pdf/informe_guatemala613esp2013.pdf>. Acesso em: 31 mar. 2020.

KILOMBA, G. Plantation memories. Episodes of Everyday Racism. Münster: 
Editora Unrast, 2010.

TAYLOR, Diana. O arquivo e o repertório: performance e memória cultural nas Américas. Belo Horizonte: Editora UFMG, 2013. 